\title{
Adverse Supply Shocks and the Financial Response: An Empirical Study
}

\begin{abstract}
Abdul Rahman Nizamani ${ }^{1}$, Erum Khushnood Zahid Shaikh ${ }^{1}$
\section{Abstract:}

The present paper has examined the role of monetary policy in mitigating the adverse supply shocks (i.e. rise in oil prices). A typical monetary policy is regarded as the stabilizing policy and it is responsible to safeguard an economy in the emergence of any negative shock from the external world. Pakistan's economy has been vulnerable to oil price fluctuations and it has often faced the long run negative impact, for instance the negative effects of 2008 commodity crises which were mainly because of the abrupt rise in oil prices. The monetary policy of Pakistan usually follows the tight policy stance as a response to such adverse supply shocks but the question always remain, how effective is it in mitigating those negative effects? In this regard, the present study has explored the effectiveness of monetary policy stance in Pakistan. In order to achieve the underline objective, this study has used the Shutdown Methodology in Structural Vector Autoregressive (SVAR) models on the quarterly data from 1992 to 2016. The results from the underline model have revealed that the monetary policy of Pakistan has a limited effectiveness on its main target variables of economic output and general price level. It is advisable to monetary authority to monitor the fluctuations of international oil prices and should engage with other transmission channels of monetary policy.
\end{abstract}

Keywords: Monetary policy, Shutdown Method, Supply Shocks, Pakistan, SVAR

JEL Classification: C32, E52, E58, F40

\section{Introduction}

The ultimate objectives of economic policies are to achieve higher and stable economic growth. The government employs two key policies to achieve the underline objectives, the fiscal and the monetary policy. Due to prominent intervention of government in fiscal matters the fiscal policy is viewed with skepticism in achieving the objectives. While central bank's monetary policy is viewed as independent in formulating and achieving the economic targets. The monetary policy is mainly used to stabilize the economy during the period of economic disruptions, either internal or external. The most common among them is the sudden change in the price of crude oil internationally,

\footnotetext{
${ }^{1}$ Department of Economics, University of Sindh, Jamshoro.
} Corresponding Email: a.nizamani@usindh.edu.pk 
widely known as supply shock. The past decade had witnessed prominent fluctuations in international oil prices. The highest prices ever recorded in 2008 and then a slump in oil prices from 2013 onwards. Both the sudden rise and fall is worse for global growth prospects. Countries that are mainly relying on the import of oil are exposed to these variations. The oil is considered as the crucial input for local industry in these economies, so any sudden change can directly transmit in the economy and reduces the income level and increases the domestic price level.

In order to insulate from these shocks, the monetary policy plays the central role in safeguarding the economy. The timely policy reaction can mitigate the negative effects and bring the economy back to its natural path. The policy reaction depends on the objective of monetary policy, if controlling inflation rate is the key objective rather output then the reaction of monetary authority will be to raise the short term interest rate and otherwise. The policy effectiveness depends on the time lag that it takes to stabilize the economy. In the case of Pakistan, it took almost five years to bring inflation back to single digit after the 2008 commodity crises.

The economy of Pakistan was severely affected by the 2008 commodity crises, and the soaring oil prices were the major culprit. It pushed the GDP growth rate to $1.7 \%$ from $6 \%$ annual projections and the inflation rate skyrocketed to $20 \%$ from $7 \%$ per annum. The monetary authority reacted in increasing the short term interest rates to double digits around $15 \%$ to control the rising price level in the economy. The prolonged tight policy stance kept the monetary authorities measures skeptical. However, the economy fully recovered from the crises soon after $2013^{2}$, but the tight monetary policy measures for the long duration undermined the economic output of Pakistan. This raises the concern to explore the role of the monetary policy in mitigating the adverse effects of the oil price shocks on the economy of Pakistan.

Previous studies with regard to Pakistan at large have reported that rising oil prices have negative impact on the domestic economy ${ }^{3}$. While the role of monetary policy during those negative events is unexplored. Therefore, this study provides a novel contribution in measuring the strength of monetary policy as a key stabilization policy that restricts the impact of negative shocks. In order to meet the underline objective, a robust SVAR (structural vector autoregressive) model has been employed with a nonrecursive identification scheme. A shutdown method of Ramey (1993) in SVAR modeling has been used to reveal the role of monetary policy during the event of adverse supply shocks.

The rest of the paper is organized as follows. Section 2 discusses the relevant literature. Section 3 provides the explanation of SVAR methodology. Section 4 explains the results from the SVAR model with the basic diagnosis. The last section provides the conclusion from the present study.

2 IMF country report 2014

3 See Siddiqui (2004), Qazi \& Riaz (2008), Zaman et al. (2011), Nazir \& Qayyum (2014) and others.

Sukkur IBA Journal of Management and Business - SIJMB | Vol 7 No. 2 July - December 2020 @ Sukkur IBA University 


\section{Literature Review}

The literature at large provides evidence that developing and emerging countries are negatively affected by the sudden change in the oil prices (Brown \& Yueel, 2002; Hooker, 2002; Cunado \& Garcia, 2005; Blanchard \& Gali, 2007; Nasir et al., 2018; Sheng et al., 2020). There are both positive and negative effects of the rise in oil prices. Countries that are net the exporter of oil witness the positive effects while the net importing countries witness negative effects. The oil importing countries whether developed or developing both witness negative effects. For instance, many studies conducted for the United States showed negative effects on the economy, See Burbidge \& Harrison (1984), Lee et al. (1995), Bernanke et al. (1997), Bachmeier (2008) and others.

Studies like Abeysinghe (2001) have shown from the cross-country evidence that developing economies are more vulnerable to rise in oil prices. This study included ten countries from the Asian region. The changes in oil prices are directly transmitted to the domestic price level which also causes economic activity to slow down. Similar findings were also concluded by Ran \& Voon (2012). Recently Cunado et al. (2015) have comprehensively studied the impact of oil shocks on the four top oil consuming countries of Asia. Including, Japan, Korea, India and Indonesia. This study used SVAR model to identify the structural shocks and concluded that supply shocks have limited impact on the economic activity of selected countries. They found that monetary policy tools are effective in mitigating the negative impact of oil prices on Korea and Japan. Apart from the impact of oil prices on the real economic variables, recently Demirer et al. (2020) have found that oil prices are also the driving force behind the global stock and bond markets. Their finding has highlighted the role of oil prices in influencing the global financial markets.

In a more recent study, Khalid et al. (2018) have examined the impact of oil shocks on the Output, price level, interest rate and exchange rates of five South Asian countries including, India, Pakistan, Sri Lanka, Bangladesh and Bhutan. Their study also relied on the SVAR model to identify the shocks and used the dynamic analysis from the impulse response functions to analyze the impact from 1982 to 2014. They found that a small shock in oil can cause significant variations in all selected variables. However, the response from each country was found different due to their respective macroeconomic policies.

Oil is a crucial input for any domestic industry, Pakistan at large relies on the imported oil, largely from the international market. Many studies have showed that sudden changes in international oil prices have adverse impact on the domestic economy of Pakistan. For instance, Nizamani et al. (2017) have found that the macroeconomic performance of Pakistan is significantly affected by the oil price shocks. Their study followed an open economy SVAR model and the generated structural impulse response functions to show the underline effects. Similarly, Khan \& Ahmed (2014) have examined the effects of oil prices on the macroeconomic variables of Pakistan using

Sukkur IBA Journal of Management and Business - SIJMB | Vol 7 No. 2 July - December 2020 @ Sukkur IBA University 
SVAR model, they also found negative effects. There are number of studies conducted on Pakistan and found similar results. (See Siddiqui (2004), Qazi \& Riaz (2008) Zaman et al. (2011) and Nazir \& Qayyum (2014). The previous literature on Pakistan shows a strong consensus about the negative effects of oil price shocks. However, there is a need to study whether the monetary policy can mitigate the negative effects of oil shocks on the economy. This will lead us to measure the strength of monetary policy during the adverse supply shock.

\section{Methodology}

\section{Data and Variables}

This study has used the quarterly data from 1992Q1 to 2016Q4, and the data have been gathered from the IMF data source. The oil prices (LOIL) is represented by the crude oil petroleum index. The industrial production index has been used to proxy the economic output (LIPI) of Pakistan. This is due to the unavailable data of GDP on a quarterly basis. The standard consumer price index has been used for the price level (LCPI) of Pakistan. The official short-term interest rate on government treasury bills (TBILL) is used to represent the interest rate level in Pakistan. The money demand (LM2) is a monetary aggregate measured as M2 of Pakistan. The exchange rates (LREER) are represented by the real effective exchange rates of Pakistan reported by the IMF. The increase in the real effective exchange rate is associated with the appreciation of the domestic currency against the basket of foreign currencies.

The selected variables are in log forms, only interest rate is kept in percentage form.

The crises dummy of 2008 global financial crises is used in the model. The data has been seasonally adjusted by standard method.

\section{SVAR (Structural Vector Autoregression) Modeling}

The structural representation of VAR model is given as;

$$
\mathrm{BX}_{\mathrm{t}}=\Gamma_{0}+\Gamma(\mathrm{L}) \mathrm{X}_{\mathrm{t}-1}+\varepsilon_{\mathrm{t}}
$$

$\mathrm{B}$ is a coefficient matrix belongs to contemporaneous variables, $\mathrm{Xt}$ is a vector of endogenous set of variables i.e Xt $=$ (LOILt LIPIt LCPIt TBILLt LM2t LREERt), $\Gamma 0$ is a deterministic vector, $\Gamma(\mathrm{L})$ is a lag operator in a polynomial matrix. $\varepsilon t$ are structural shocks with the condition $\mathrm{M}(\varepsilon \mathrm{t})=0$ and $\mathrm{M}\left(\varepsilon \mathrm{t} \varepsilon \mathrm{t}^{6}\right)=\Sigma \varepsilon$, that is Identity matrix. Transforming equation (1),

$$
\mathrm{X}_{\mathrm{t}}=\mathrm{B}^{-1} \Gamma_{0}+\mathrm{B}^{-1} \Gamma(\mathrm{L}) \mathrm{X}_{\mathrm{t}-1}+\mathrm{B}^{-1} \varepsilon_{\mathrm{t}}
$$

Further simplification yields,

$$
X_{t}=A_{0}+A_{1} X_{t-1}+e_{t}
$$


$\mathrm{A}_{0}=\mathrm{B}^{-1} \Gamma_{0}, \mathrm{~A}_{1}=\mathrm{B}^{-1} \Gamma(\mathrm{L})$ and $\mathrm{e}_{\mathrm{t}}=\mathrm{B}^{-1} \varepsilon_{\mathrm{t}}$ with the condition of $\mathrm{M}\left(\mathrm{e}_{\mathrm{t}}\right)=0, \mathrm{M}\left(\mathrm{e}_{\mathrm{t}}\right.$ $\left.\mathrm{e}_{\mathrm{t}}{ }^{\mathrm{c}}\right)=\Sigma \mathrm{e}$.

Equation (3) can be estimated using the data, while the structural shocks ( $\mathrm{\varepsilon t}$ ) are used rather than estimated residuals (et) to generate the impulse response functions (Enders 2004). Structural shocks ( $\varepsilon t$ ) can be recovered from estimated residuals (et) as:

$$
\Sigma_{\mathrm{e}}=\mathrm{M}\left(\mathrm{e}_{\mathrm{t}} \mathrm{e}_{\mathrm{t}}^{\prime}\right)=\mathrm{M}\left(\mathrm{B}^{-1} \varepsilon_{\mathrm{t}} \varepsilon_{\mathrm{t}}^{\prime} \mathrm{B}^{-1^{\prime}}\right)=\mathrm{B}^{-1} \Sigma_{\varepsilon}\left(\mathrm{B}^{-1}\right)^{\prime}
$$

Hence,

$$
\Sigma_{\varepsilon}=\mathrm{B} \Sigma_{\mathrm{e}} \mathrm{B}^{\prime}
$$

To just identify the system, further restrictions are required of the form n2-n/2, so as to retrieve all structural shocks ( $(\mathrm{t})$ from the estimated residuals (et). As matrix $\Sigma_{\mathrm{e}}$ have $\mathrm{n} 2+\mathrm{n} / 2$ unknown elements.

The SVAR model allows using economic theory to impose restrictions on the system that gives non-recursive structure on contemporaneous parameters, rather than the Cholesky decomposition that is to orthogonalize the estimated residuals from the reduced form VAR providing recursive structure of the identification.

The equation (3) is used to recover structural shocks. Given as, $e_{t}=B^{-1} \varepsilon_{t}$, or $\varepsilon_{t}=$ $B e_{t}$. The appropriate restrictions are applied on B matrix that is shown below in the compact matrix form.

$$
\left[\begin{array}{c}
\varepsilon_{L O I L} \\
\varepsilon_{L I P I} \\
\varepsilon_{L C P I} \\
\varepsilon_{T B I L L} \\
\varepsilon_{L M 2} \\
\varepsilon_{L R E E R}
\end{array}\right]=\left[\begin{array}{cccccc}
1 & 0 & 0 & 0 & 0 & 0 \\
a_{21} & 1 & 0 & 0 & 0 & 0 \\
a_{31} & a_{32} & 1 & 0 & 0 & 0 \\
0 & a_{42} & a_{43} & 1 & 0 & 0 \\
0 & a_{52} & a_{53} & a_{54} & 1 & 0 \\
a_{61} & a_{62} & a_{63} & a_{64} & a_{65} & 1
\end{array}\right]\left[\begin{array}{c}
\boldsymbol{e}_{L O I L} \\
\boldsymbol{e}_{L I P I} \\
\boldsymbol{e}_{L C P I} \\
\boldsymbol{e}_{T B I L L} \\
\boldsymbol{e}_{L M 2} \\
\boldsymbol{e}_{L R E E R}
\end{array}\right]
$$

The zero restrictions on matrix B in eq (6) are employed by following the method of Amisano \& Giannini (1996), the system requires minimum n2-n/2 $=62-6 / 2=15$ zero restrictions to be exactly identified, where as in this case 17 restrictions are enough to over-identified SVAR system. The details of the above identification are explained below.

The first row includes oil prices (LOIL), that is to show that oil is relatively exogenous in the system. This identification is guided from the prior study of Kim \& Roubini (2000). The remaining macroeconomic variables of Pakistan are as follows. The economic output (LIPI) and the domestic prices (LCPI) show the equilibrium condition

Sukkur IBA Journal of Management and Business - SIJMB | Vol 7 No. 2 July - December 2020 @ Sukkur IBA University 
in the goods market. The response of second and third row is contemporaneous. This is due to the fact that a variation in (LOIL) can potentially impact the output and price level in Pakistan. The row fourth and fifth represents the money market condition. Where short term interest rate (TBILL) represent the reaction function of Pakistan's monetary policy, which contemporaneously responds to the changes in domestic output and price level. It responds to all other variables in the lag. Row fifth shows the money demand (LM2) equation. The exchange rate (LREER) is set in the bottom due to the fact that the exchange rate variations are reported more frequently than all remaining variables.

To uncover the strength of monetary policy in restricting the adverse effects of oil prices. This study uses the proposed shutdown method of Ramey (1993) in SVAR modeling. In this method the proposed variable is muted or switched off to gauge its contribution in the system. The impulse response functions generated from this method will allow analyzing them with baseline impulse response functions. For instance, the oil price shock will be analyzed under two settings. One, the effects of oil prices will be analyzed from the baseline SVAR model (i.e. equation (6)) where monetary policy is present in the model. Second, the same effect will be analyzed from the model where monetary policy (i.e. TBILL \& LM2) is exogenised in (6). The variations in the impulse response functions will show the strength of monetary policy in mitigating the adverse supply shocks. The same method has been used in SVAR recently by Perera \& Wickramanayake (2013) and Nizamani et al. (2016).

\section{Empirical Results}

The analyses are done under two settings. First, the impact of adverse supply shocks on all macroeconomic variables of Pakistan are analysed with IRF (Impulse Response Functions). Second, the relative impact of supply shocks are analysed with the shutdown method. Before discussing the final results from IRF it is pivotal to reveal the stationarity of the variables and some essential diagnosis of the SVAR model. Table 1 reports the unit root test results from the commonly used ADF (Augmented Dickey Fuller), the test results reports that all variables are I(1) only (LOIL) is I(0) at $10 \%$ significance level. This study has used variables in their level form following the prior studies of Sims et al. (1990) and Lutkepohl \& Reimers (1992). Because there is a tradeoff between estimating VAR in level form and in first difference, there is loss efficiency in the level form VAR and loss of long run information in first difference.

Sukkur IBA Journal of Management and Business - SIJMB | Vol 7 No. 2 July - December 2020 @ Sukkur IBA University 
Table 1: Unit Root Test (Augmented Dickey Fuller)

\begin{tabular}{|l|c|c|c|c|}
\hline \multirow{2}{*}{ Variables } & \multicolumn{2}{|c|}{ With Trend (SIC) } & \multicolumn{2}{c|}{ Without Trend (SIC) } \\
\cline { 2 - 5 } & Statistics & P-values & Statistics & P-values \\
\hline LOIL & $-3.605 *(1)$ & 0.093 & $-2.606(0)$ & 0.856 \\
\hline$\Delta$ LOIL & $-5.816^{* * *}(0)$ & 0.001 & $-5.863 * * *(0)$ & 0.001 \\
\hline LIPI & $-1.394 *(1)$ & 0.856 & $-0.503(1)$ & 0.884 \\
\hline$\Delta$ LIPI & $-12.370 * * *(0)$ & 0.001 & $12.578^{* * *(0)}$ & 0.001 \\
\hline LCPI & $-1.459(1)$ & 0.836 & $-0.116(1)$ & 0.943 \\
\hline$\Delta$ LCPI & $-4.254 * *(0)$ & 0.001 & $-4.238^{* * *(0)}$ & 0.001 \\
\hline TBILL & $-2.117(1)$ & 0.537 & $-2.124(1)$ & 0.241 \\
\hline$\Delta$ TBILL & $-6.701 * * *(0)$ & 0.000 & $-6.736 * * *(0)$ & 0.000 \\
\hline LM2 & $-1.726(1)$ & 0.731 & $-0.486(1)$ & 0.888 \\
\hline$\Delta$ LM2 & $-6.835^{* * *(0)}$ & 0.000 & $-6.861 * * *(0)$ & 0.000 \\
\hline LREER & $-0.330(0)$ & 0.988 & $-1.761(1)$ & 0.397 \\
\hline$\triangle$ LREER & $-7.577 * * *(0)$ & 0.000 & $-7.335^{* * *(0)}$ & 0.000 \\
\hline
\end{tabular}

Table 2: LM test for Autocorrelation

\begin{tabular}{|c|c|c|}
\hline Time Lag & Test Statistics & Probability \\
\hline 1 & 112.8353 & 0.0001 \\
\hline 2 & 67.22080 & 0.3258 \\
\hline 3 & 79.32632 & 0.0939 \\
\hline 4 & 74.95145 & 0.1951 \\
\hline 5 & 62.21823 & 0.5241 \\
\hline
\end{tabular}

Note: Lagrange Multiplier Test follows the standard procedure of hypothesis testing

The different information criterions were used for the selection of optimal lag length. Including, Akaike, Schwarz and Hannan-Quinn have reported different optimal lag length. Due to the conflicting results, this study has relied on the Lagrange Multiplier (LM) test to identify the optimal lag length.

Sukkur IBA Journal of Management and Business - SIJMB | Vol 7 No. 2 July - December 2020 @ Sukkur IBA University 
Table 2 reports the LM test results up to lag five for the serial correlation. The optimal lag length two has been selected for the estimation of the SVAR model and it is enough for the quarterly data (Disyatat \& Vongsinsirikul, 2003). The stability of SVAR model with lag length two in Table A1, confirms that the model is stable with the selected lag length.

As the underline SVAR model is overidentified, so as to confirm whether the restrictions are valid or not the likelihood ratio statistics are employed. The likelihood ratio reports the value of 0.5580 with a 0.75 (P-value) of the baseline SVAR model. Hence, confirming that the additional restrictions are valid on the selected SVAR model. The estimated coefficients of SVAR model are shown in a table below.

Table 3: Estimations from SVAR Model

\begin{tabular}{|c|c|c|c|c|c|}
\hline LOIL & LIPI & LCPI & TBILL & LM2 & LREER \\
\hline 1 & 0 & 0 & 0 & 0 & 0 \\
\hline $\begin{array}{l}-0.0316 \\
(0.0273)\end{array}$ & 1 & 0 & 0 & 0 & 0 \\
\hline $\begin{array}{l}-0.0190 \\
(0.0062) \\
\end{array}$ & $\begin{array}{c}0.0220 \\
(0.0238) \\
\end{array}$ & 1 & 0 & 0 & 0 \\
\hline 0 & $\begin{array}{l}-9.1728 \\
(6.2033)\end{array}$ & $\begin{array}{c}-42.0412 \\
(26.3202)\end{array}$ & 1 & 0 & 0 \\
\hline 0 & $\begin{array}{c}-0.0464 \\
(0.0370) \\
\end{array}$ & $\begin{array}{c}0.6352 \\
(0.1573) \\
\end{array}$ & $\begin{array}{c}0.0016 \\
(0.0006) \\
\end{array}$ & 1 & 0 \\
\hline $\begin{array}{c}0.0536 \\
(0.0141)\end{array}$ & $\begin{array}{c}0.0171 \\
(0.0527)\end{array}$ & $\begin{array}{l}-0.4360 \\
(0.2492)\end{array}$ & $\begin{array}{c}0.0020 \\
(0.0009)\end{array}$ & $\begin{array}{c}-0.0357 \\
(0.1475)\end{array}$ & 1 \\
\hline
\end{tabular}

Note: standard errors are reported in small brackets.

\section{Impulse Response Functions}

Figure 1 and onwards provides the IRF that are generated from the underline SVAR model. The estimated response of all selected variables to a one-time shock in (LOIL) is reported in the Figure 1. The one-time shock in (LOIL) implies the sudden rise in oil prices internationally. The middle line of each figure shows the corresponding response from each variable. The two confidence bands in each figure are calculated from a bootstrapping technique.

The first row of Figure 1 shows the response of domestic output and price level to the one-time positive shock in (LOIL). Economic output (LIPI) of Pakistan shows a significant negative response to oil price shock. The initial response is positive but insignificant and short lived. Whereas in the middle to long run horizon, it is negative and significant in addition it slowly goes up as the effects are reduced in the long run.

Sukkur IBA Journal of Management and Business - SIJMB | Vol 7 No. 2 July - December 2020 @ Sukkur IBA University 
The response of Pakistan's output is as expected because when a price of international oil increases it will adversely impact the local output. There is ample evidence in the literature that adverse supply shock reduces the output of oil importing country. The price level in Pakistan shows a significant positive response to the rise in oil prices. This is also an expected response because the price level in the country primarily responds positively with a rise in oil price.

A positive response from (TBILL) in Figure 1 shows the policy stance by the monetary authority of Pakistan. Since the priority of monetary policy in Pakistan has been to control inflation so the positive response shows that the monetary policy raises the short term interest rates to counter the effects of oil prices on the domestic price level. The response of money demand (LM2) to oil price shock is negative; this is due to the slowdown in the real activity in the economy. As the pace of overall economy slows so as the demand for money also goes down. The last row in Figure 1 shows the response of exchange rate (LREER) to rise in the oil price shock. The initial positive response shows that the home currency depreciates against other currencies.

The positive and significant response implies that as the prices of international oil raises the demand for foreign currencies also raises comparatively to that of a local currency. Which in turn results depreciation in Pakistani currency.

The VDC (variance decomposition) from SVAR for output (LIPI) and price level (LCPI) are given in the Table A2 and A 3 of the appendix. It is evident from these tables that oil prices (LOIL) are the major source of variation in both economic output and general price level.

The relative responses from the output and price level of Pakistan are shown in the figure 2 and 3. There are two impulse responses in each figure and they are labeled accordingly. The first response is from the baseline SVAR model represented with solid line, while the second response is generated through the shutdown method represented with dashed line, where the monetary policy is muted. This is done to measure the strength of monetary policy in restricting the adverse effects of rise in oil prices. The Figure 2 shows that at the end of first year (i.e. fourth quarter) the response of domestic output is more than three-fourths of the response in baseline IRF. At the end of second year (i.e. eight quarter) it reduces to the half of the baseline response. Whereas, in the medium run (i.e. end of the fifth year) the response of domestic output in the baseline is three times higher than that without monetary policy. However, in the long run, the response of output is positive in the baseline compared to that of without monetary policy. It implies an effective monetary policy in the short-run that mitigates the adverse supply shock on the domestic output. But in the medium run the monetary policy is found to be ineffective. This is due to the weak output structure of the economy that requires some periods to recover from the shock. 


\section{Response of LIPI}

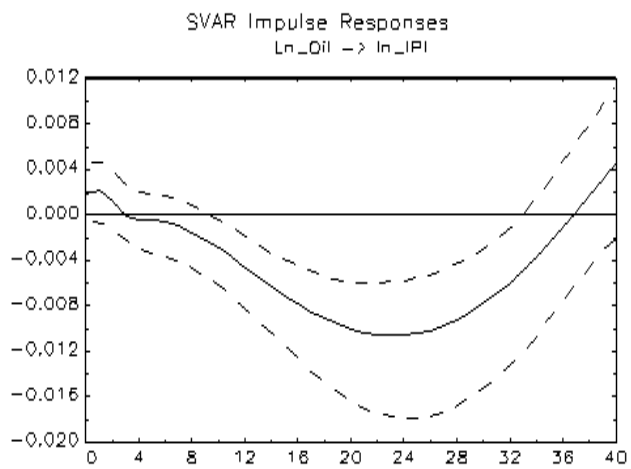

Response of TBILL

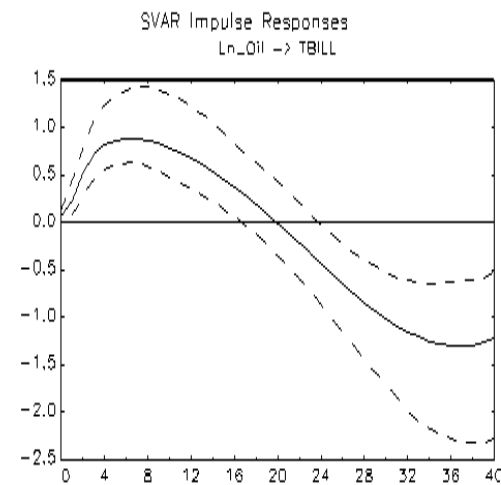

Response of LREER

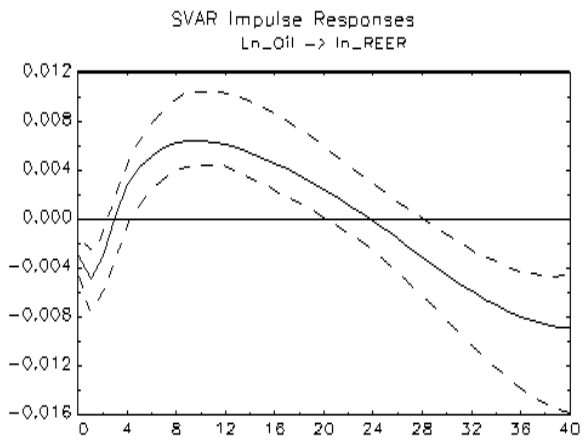

\section{Response of LCPI}

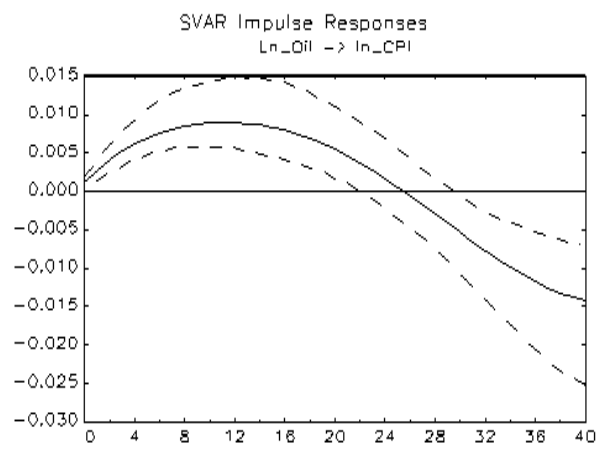

Response of LM2

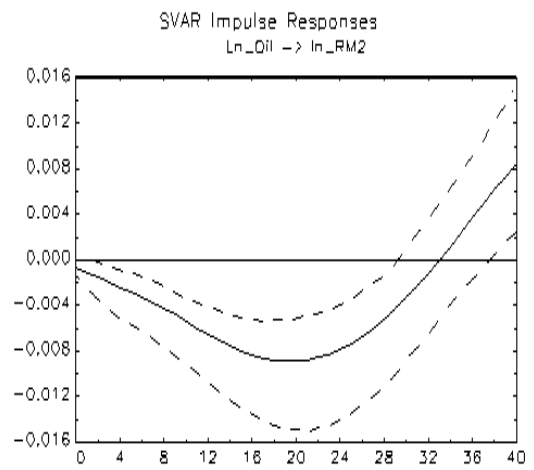

Figure 1: Response of Macroeconomic Variables to Shocks in Oil Prices

Sukkur IBA Journal of Management and Business - SIJMB | Vol 7 No. 2 July - December 2020 @ Sukkur IBA University 


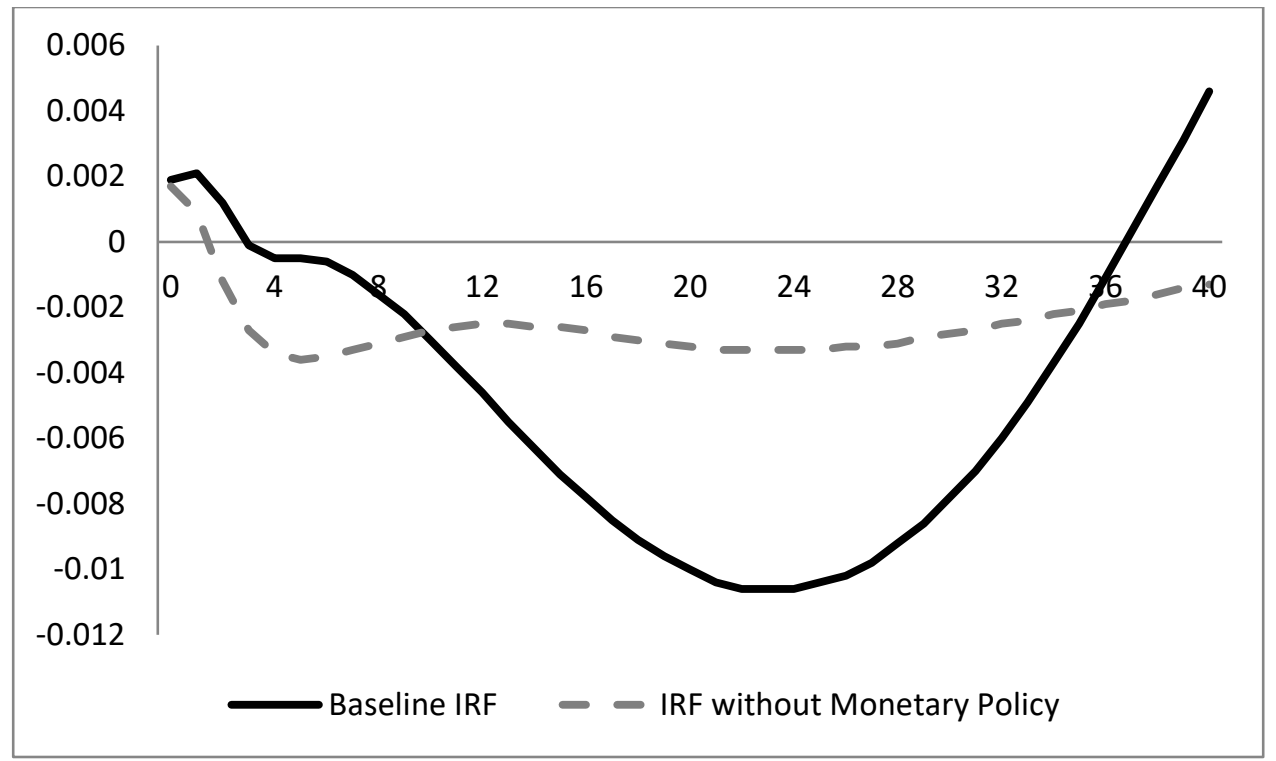

Figure 2: Relative Response from LIPI (Output)

In Figure 3, the response of price level in the baseline IRF is almost one-fourth times higher than that in IRF without monetary policy. It gradually increases till the end of fifth year and the baseline IRF start to decline onwards. Price level goes down after the seventh year in the baseline compared to that without monetary policy. This implies that the monetary policy is effective in reducing the domestic price level in the medium to long run, whereas in the short run it failed to mitigate the adverse effects of oil prices. This suggests us that there is a direct pass-through of the rise in oil prices to the domestic prices.

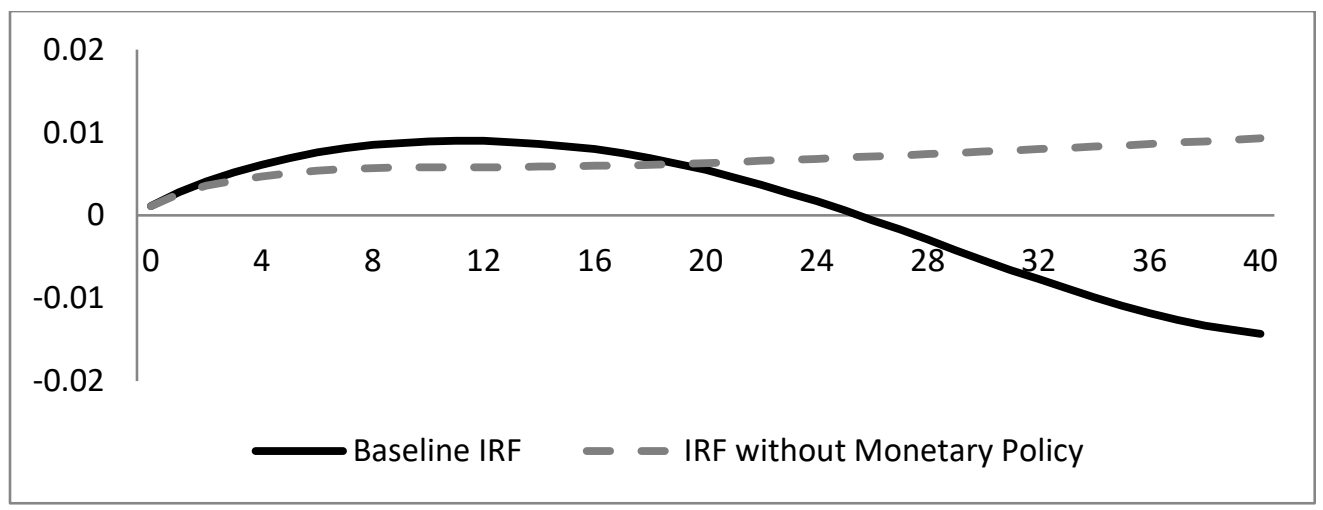

Figure 3: Relative Response from LCPI (Price level)

Sukkur IBA Journal of Management and Business - SIJMB | Vol 7 No. 2 July - December 2020 @ Sukkur IBA University 


\section{Conclusion}

This study has mainly examined the role of monetary policy in mitigating the adverse effects of rise in oil prices on the economy of Pakistan. The underline objective is met using the shutdown methodology in SVAR modeling. The said method is most appropriate to study the strength of monetary policy in limiting the negative effects of oil shocks. The dynamic analysis has been carried out mainly on impulse response functions which are generated from the non-recursive identification in SVAR modeling. The results have revealed the following findings. Initially, the effects of oil shocks have been analyzed on macroeconomic variables (i.e. economic output, price level, interest rate, money demand and exchange rates). Oil shocks cause the economic output to go down significantly and it increases the price level. These effects were found as anticipated from the past studies. The interest rate showed a positive response to oil price shock while money demand showed a negative response. It implies that monetary policy responds with tight policy stance to a shock in oil prices. This is in line with the primary objective of monetary policy practice in Pakistan. From the shutdown method, this study has found that the monetary policy is only effective in the short run to mitigate the negative effects of oil price shocks on the economic output of Pakistan. On the other hand, the effectiveness of monetary policy is restricted to medium to long run for the domestic price level. Considering the findings of this study, it is advisable that the monetary authority must closely monitor the turbulence in the international oil prices and should engage with other transmission channels (i.e. exchange rate) to counter the negative effects on the price level.

\section{References:}

Abeysinghe, T. (2001). Estimation of direct and indirect impact of oil price on growth. Economic Letters, 73, 147-153.

Amisano, G., \& Giannini, C. (1996). Topics in Structural VAR Econometrics. Springer,Berlin.

Bachmeier, L. (2008). Monetary policy and the transmission of oil shocks. Journal of Macroeconomics, 30, 1738-1755.

Bernanke, B. S., Gertler, M., \& Watson, M. (1997). Systematic monetary policy and the effects of oil price shocks. Brookings Papers on Economic Activity, 1, 91157.

Blanchard, O. J., \& Gali, J. (2007). The Macroeconomic Effects of Oil Shocks: Why are the 2000s so Different from the 1970s? NBER Working Paper 13368.

Brown, S. P. , \& Yucel, M. K. (2002). Energy prices and aggregate economic activity: An interpretative survey. Quarterly Review of Economics and Finance, 42(2), 193-208.

Burbidge, J., \& Harrison, A. (1984). Testing for the effects of oil price rises using vector autoregressions. International Economic Review, 25, 459-484.

Sukkur IBA Journal of Management and Business - SIJMB | Vol 7 No. 2 July - December 2020 @ Sukkur IBA University 
Cunado, J., \& Gracia, F. P. De. (2005). Oil prices, economic activity and inflation: evidence for some Asian countries, 45, 65-83.

Cunado, J., Jo, S., \& Garcia, F.P. (2015). Macroeconomic impacts of oil price shocks in Asian economies. Energy Policy, http: //dx.doi.org/10.1016/j.enpol.2015.05.004

Demirer, R., Ferrer, R., \& Shahzad, S.J.H. (2020). Oil Price Shocks, Global Financial Markets and their Connectedness. Energy Economics, 88, 104771.

Disyatat, P., \& Vongsinsirikul, P. (2003). Monetary policy and the transmission mechanism in Thailand. Journal of Asian Economics, 14(3), 389-418.

Enders, W. (2004). Applied Econometrics Time Series.(Second Edition).

Hooker, M. A. (2002). Are Oil Shocks Inflationary? Asymmetric and Nonlinear Specifications versus Changes in Regime. Journal of Money, Credit and Banking, 34(2), 540-561.

Khalid, A., Bhutto, N.A., \& Kalhoro, M.R. (2018). Decomposing the links between oil price shocks and macroeconomic indicators: Evidence from SAARC region. Resources Policy, https://doi.org/10.1016/j.resourpol.2018.03.001

Khan, M. A., \& Ahmed, A. (2014). Revisiting the macroeconomic effects of oil and food price shocks to Pakistan economy: a structural vector autoregressive (SVAR) analysis. OPEC Energy Review, 184-215.

Kim, S., \& Roubini, N. (2000). Exchange rate anomalies in the industrial countries : A solution with a structural VAR approach. Journal of Monetary Economics, 45.

Lee, K., Ni, S., \& Ratti, R.A. (1995). Oil shocks and the macroeconomy: The role of price variability. Energy Journal, 16, 39-56.

Lütkepohl, H., \& Reimers, H.-E. (1992). Impulse response analysis of cointegrated systems. Journal of Economic Dynamics and Control, 16(1), 53-78. doi:10.1016/0165-1889(92)90005-Y

Nasir, M.A., Naidoo, L., Shahbaz, M., \& Amoo, N. (2018). Implications of Oil Prices Shocks for the Major Emerging Economies: A Comparaive Analysis of BRICS. Energy Economics, 76, 76-88.

Nazir, S., \& Qayyum, A. (2014). Impact of Oil Price and Shocks on Economic Growth of Pakistan: Multivariate Analysis. Munich Personal RePEc Archive, Paper No 5.

Nizamani, A.R., Zulkefly, A.K., Zaidi, M.A.S., \& Khalid, N. (2016). The effectiveness of monetary policy in small open economy: An SVAR study for Pakistan. International Journal of Economics and Management, 10(2), 279-296.

Nizamani, A.R., Gilal, M.A., Khushik, A.G., Syed, M.S., and Abid, A. (2017). External shocks and the macroeconomic response of small open economy: A structuralVAR approach for Pakistan. Asian Journal of Scientific Research, 10, 336-344.

Perera, A., \& Wickramanayake, J. (2013). Monetary Transmission in The Emerging Country Context: The Case of Sri Lanka. Central Bank of Sri Lanka International Research Conference-2013, 1-80.

Sukkur IBA Journal of Management and Business - SIJMB | Vol 7 No. 2 July - December 2020 @ Sukkur IBA University 
Qazi, M. A. H., \& Riaz, S. (2008). Causality between Energy Consumption and Economic Growth: The Case of Pakistan. The Lahore Journal of Economics, 2(Winter), 45-58.

Ramey, V. (1993). How important is the credit channel in the transmission of monetary policy? Carnegie-Rochester Conference Series on Public Policy, 39.

Sheng, X., Gupta, R., \& Ji, Q. (2020). The Impacts of Structural Oil Shocks on Macroeconomic Uncertainity: Evidence from a Large Panel of 45 Countries. Energy Economics, 91, 104940.

Siddiqui, R. (2004). Energy and Economic Growth in Pakistan. The Pakistan Development Review, 2(Summer), 175-200.

Sims, C. A., Stock, J. H., \& Watson, M. W. (1990). Inference in Linear Time Series Models With Some Unit Roots. Econometrcia, 58(1), 113-144.

Zaman, B., Farooq, M., \& Ullah, S. (2011). Sectoral oil consumption and economic growth in Pakistan: An ECM approach. American Journal of Scietific and Industrial Research, 2, 149-156.

Sukkur IBA Journal of Management and Business - SIJMB | Vol 7 No. 2 July - December 2020 @ Sukkur IBA University 


\section{APPENDIX}

Table A1: Stability Test for SVAR

\begin{tabular}{|l|l|}
\hline Root & Modulus \\
\hline 0.991820 & 0.991820 \\
\hline $0.953941-0.095671 \mathrm{i}$ & 0.958727 \\
\hline $0.953941+0.095671 \mathrm{i}$ & 0.958727 \\
\hline 0.878934 & 0.878934 \\
\hline $0.828141-0.081404 \mathrm{i}$ & 0.832132 \\
\hline $0.828141+0.081404 \mathrm{i}$ & 0.832132 \\
\hline $0.656901-0.291368 \mathrm{i}$ & 0.718620 \\
\hline $0.656901+0.291368 \mathrm{i}$ & 0.718620 \\
\hline $0.482107-0.399748 \mathrm{i}$ & 0.626279 \\
\hline $0.482107+0.399748 \mathrm{i}$ & 0.626279 \\
\hline 0.561980 & 0.561980 \\
\hline $0.087829-0.495862 \mathrm{i}$ & 0.503580 \\
\hline $0.087829+0.495862 \mathrm{i}$ & 0.503580 \\
\hline-0.367168 & 0.367168 \\
\hline 0.112604 & 0.112604 \\
\hline 0.050609 & 0.050609 \\
\hline$*$ SVAR model meets the stability requirement. All root lies within the unit circle. \\
\hline
\end{tabular}

Sukkur IBA Journal of Management and Business - SIJMB | Vol 7 No. 2 July - December 2020 @ Sukkur IBA University 
Table A2: Variance Decomposition of LIPI

\begin{tabular}{|c|c|c|c|c|c|c|}
\hline Steps & LOIL & LIPI & LCPI & TBILL & LM2 & LREER \\
\hline 1 & 0.01 & 0.99 & 0.00 & 0.00 & 0.00 & 0.00 \\
\hline 10 & 0.03 & 0.43 & 0.24 & 0.02 & 0.23 & 0.05 \\
\hline 20 & 0.31 & 0.17 & 0.28 & 0.04 & 0.14 & 0.06 \\
\hline 30 & 0.42 & 0.07 & 0.16 & 0.04 & 0.25 & 0.06 \\
\hline 40 & 0.36 & 0.06 & 0.18 & 0.05 & 0.29 & 0.05 \\
\hline
\end{tabular}

Table A3: Variance Decomposition of LCPI

\begin{tabular}{|c|c|c|c|c|c|c|}
\hline Steps & LOIL & LIPI & LCPI & TBILL & LM2 & LREER \\
\hline 1 & 0.09 & 0.01 & 0.90 & 0.00 & 0.00 & 0.00 \\
\hline 10 & 0.48 & 0.10 & 0.25 & 0.02 & 0.13 & 0.03 \\
\hline 20 & 0.43 & 0.12 & 0.11 & 0.01 & 0.30 & 0.04 \\
\hline 30 & 0.32 & 0.13 & 0.18 & 0.01 & 0.32 & 0.03 \\
\hline 40 & 0.37 & 0.15 & 0.22 & 0.01 & 0.20 & 0.04 \\
\hline
\end{tabular}

Sukkur IBA Journal of Management and Business - SIJMB | Vol 7 No. 2 July - December 2020 @ Sukkur IBA University 